\title{
A imagem além do tempo: a construção do imaginário do futuro nos produtos midiáticos
}

\section{Eduardo Duarte}

Doutor; Universidade Federal de Pernambuco, Recife, PE, Brasil edwartte@gmail.com

\section{Nathan Cirino}

Doutorando; Universidade Federal de Campina Grande, Campina Grande, PB, Brasil nathancirino@yahoo.com.br

\section{Resumo}

O imaginário tem servido à humanidade como uma grande fonte de especulações para o futuro. Ao longo dos séculos, invenções tidas como impossíveis se tornaram realidade e deixaram os papéis para assumir seus espaços físicos na vida cotidiana das pessoas. Seja nos desenhos de Da Vinci, na literatura de Júlio Verne ou nos filmes de Méliès, a mídia de ficção científica tem servido como catalisadora para transformações reais da tecnologia e da sociedade, além de nos auxiliar a pensar o próprio presente com base nas nossas projeções do que está por vir. Este texto se debruça sobre o imaginário e algumas expressões midiáticas, em especial o cinema, para apontar uma perspectiva de interpretação de narrativas futurísticas que vai além de seu efêmero momento lúdico de fruição. $\mathrm{O}$ ato aparentemente simples de imaginar $\mathrm{e}$ simular o futuro através das mídias, dessa forma, pode se revelar um forte exercício de ensaio da mente humana para aquilo que ela eventualmente alcançará.

\section{Palavras-chave}

Imaginário. Futuro. Cinema.

\section{Introdução}

Quando Leonardo visitou Veneza, no século XVI, imaginou uma forma de combate surpresa aos navios do império Otomano que ameaçavam invadir a cidade pelo mar. Uma estranha roupa de couro com tubos condutores de ar ligados a grandes bolsas na superfície 
permitiria que soldados italianos pudessem caminhar por baixo d'água e tomar os navios turcos de surpresa. Esse empreendimento de combate nunca foi realizado, mas de alguma forma a imaginação de Da Vinci fez surgir uma ideia que passou a ser real a partir do seu projeto, mesmo que tenha se materializado no primeiro escafandro apenas 400 anos depois.

Os projetos militares de Leonardo não se distinguiam de sua criação artística. Pensar cientificamente suas armas de guerra era recriar condições naturais e lógicas de reinterpretar tecnologicamente o mundo (CAPRA, 2008). Ele desenvolveu o projeto de uma de suas máquinas voadoras pilotadas por quatro homens em 1510, e tal invenção saiu do solo pela primeira vez em 1907, na França, e veio a chamar-se helicóptero.

O plano quimérico de um veículo submarino, por sua vez, é anterior a Leonardo. Foi concebido como projeto pela primeira vez em 1578, pelo matemático inglês William Bourne, mas da Vinci também acrescentou ideias a esse projeto, e cada artista-engenheiro que o retomou engravidou o imaginário no século $\mathrm{XV}$, e os seguintes, de novos elementos na sua concepção. Assim se faz o engenho da imaginação tecnológica dos seres humanos. Um projeto que se constrói e que nunca termina, ele resulta do acúmulo de desejos, sonhos, inspirações de esboços técnicos no repertório de imagens pluridimensionais do imaginário. Esse engenho vai aqui e ali gerando máquinas que são aperfeiçoadas em seguida, e depois adormecem como quimeras à espera de outra época, de novas condições tecnológicas para se tornarem materiais.

Em 1776, o americano David Bushnell fez o primeiro protótipo de um submarino funcionar com capacidade para uma pessoa, mas com pouca autonomia de deslocamento. Mas o projeto voltou até fazer Júlio Verne imaginar, em 1870, o seu Nautilus dando uma volta no planeta sob as águas, na ficção científica 20 mil léguas submarinas. Tal imagem fecundou novamente o imaginário, provocou avanços e descobertas tecnológicas que permitiram, em 1960, que o primeiro submarino movido a energia nuclear realizasse, pela primeira vez, a viagem idealizada por Verne.

A obra de Júlio Verne traz inúmeras antecipações tecnológicas e às vezes com detalhes descritivos que décadas depois vieram a se realizar como se a ficção fosse uma premonição de acontecimentos. Os seus livros Da terra à lua, de 1865, e Viagem ao redor da lua, de 1870, descrevem o que seria a primeira expedição do homem até ela. Em sua ficção, Verne imaginou que uma cápsula com três tripulantes daria a volta em torno do satélite terrestre e voltaria à Terra caindo no mar, onde seus tripulantes seriam resgatados por um navio de guerra. Um século depois, em 1969, a Apollo 8, tripulada por três astronautas, 
realizou essa projeção futurista regressando à Terra com pouso no Pacífico e sendo resgatada exatamente por um navio de guerra.

A ficção científica trouxe outras antecipações nas páginas de autores diversos. H. G. Wells apresenta o funcionamento do laser em Guerra dos mundos (1898). Arthur Clarke imaginou tecnologias espaciais que foram surgindo em filmes e diretamente nos projetos de engenharia espacial. Clarke descreveu a ideia de equipamentos em órbita fixa da Terra com o objetivo de melhorar as telecomunicações, e assim a imaginação esboçou os primeiros satélites. No conto A sentinela (1951), Clarke gerou o embrião imaginário do que veio a ser o filme 2001: uma odisseia no espaço (1968), de Stanley Kubrick. O filme prevê naves tripuladas por um supercomputador capaz de criar autonomia da vontade dos humanos e derrotá-los. Esse filme atualizou o imaginário mítico do embate do homem com a máquina, e passou a ser fonte de inspiração para a celeuma em torno do computador da IBM que derrotou o campeão de xadrez Gary Kasparov em 1997.

Em Admirável mundo novo, de 1932, Aldous Huxley descreve uma sociedade sombria dividida em castas, com uma política totalitária que recorre à lavagem cerebral e manipulação genética para manter a população submissa. Admirável mundo novo é uma obra que sempre vem à lembrança por seus inúmeros aspectos sugestivos das profundas mudanças que a sociedade ocidental viveu a partir da segunda metade do século XX. Traz ainda a ideia da liberação sexual dos anos 1960, a popularização das drogas químicas, a clonagem e uma ideia ainda embrionária de realidade virtual que aparece com o nome de cinema-sensível.

Mesmo caminho das sociedades distópicas segue George Orwell no seu romance 1984 (1948). Nessa obra, o mundo sombrio é ainda enfatizado pela paranoia de perseguição do olhar de câmeras de vigilância espalhadas por todos os lados, controlando os passos de todos os cidadãos e antecipando a realidade dos serviços de segurança pública por monitoramento de imagens dos grandes centros urbanos contemporâneos.

O movimento da criação é ininterrupto. 0 submarino, o escafandro e o laser não são pontos finais do exercício da imaginação. Eles são acontecimentos possíveis que saltam do processo criativo que continua ao infinito a engendrar formas com desejos, medos e paixões com necessidades práticas do cotidiano, sonhos com valores morais e ódios de guerra. A usina criativa incessante do imaginário pluridimensional da espécie humana lança no mundo invenções como uma fogueira libera fagulhas no espaço. Elas surgem em infinitas formas e graus diferentes de materialização, indo de projetos a protótipos que estimulam 
novos projetos e novos protótipos, num ir e vir na imaginação que se torna real em graus diversos de materialidade. A invenção tecnológica que se materializa encanta, aterroriza e esse conjunto de efeitos sensíveis no mundo grava-se em sua imagem quando ela retorna ao imaginário engravidando-o de novos aspectos, e lá fica à espera de condições criativas, para novos esboços, e tecnológicas, para novas materializações.

\section{Caminhos conceituais para o imaginário}

Quando aqui falamos de imaginário precisamos apontar um caminho conceitual que defina um termo, que ofereça uma compreensão do lugar em que enxergamos esse fenômeno. Tentaremos agora definir um lugar de fala para esse conceito que é por demais esgarçado. Para essa tarefa, entretanto, não gostaríamos de construir uma filiação teórica pertinente a uma escola específica, posto que por mais que o termo imaginário tenha sido usado de formas tão distintas e com fundos epistemológicos diversos, há algumas ideias comuns apresentadas por hermenêuticas diferentes que gostaríamos de usar como base da compreensão que temos. Apontaremos duas ou três conceituações que parecem indicar o mesmo fenômeno, ou seja, descrevem de forma muito parecida os mesmos aspectos que nos interessam dessa instância humana criativa. Percebemos uma certa contiguidade de forças que as imagens desses conceitos inspiram, retroalimentam-se e complementam-se. Mesmo estando em elaborações teóricas distintas descrevem fenômenos similares.

Então, o imaginário para nós é um repertório de imagens que se constituem afetivamente como lastro psíquico de nossa espécie. Esse banco de imagens atemporal é formado por toda herança de referências criadas pelo homo sapiens, de todos os aspectos da vida que migraram pela afetividade para dimensões inconscientes dos coletivos humanos. 0 imaginário é composto pelas percepções estruturantes da vida social, constituintes de nossos valores, medos e perspectivas. Mas o imaginário, da maneira como o percebemos não se distingue de um mundo real. Como se houvesse um mundo real e outro imaginado. 0 que chamamos de mundo real é um aspecto do imaginário que é social e historicamente pactuado para chamar de realidade. Nesse sentido, o imaginário calça o real como a mão calça uma luva. $O$ real é uma dimensão possível e coletivamente escolhida e compartilhada das nossas criações, do que imaginamos e legitimamos como verdade.

Há uma forte correspondência dessa ideia com que apresenta Jung em seu conceito de arquétipo. A teoria de Jung em relação às imagens é uma das mais profundas já 
concebidas. Ele parte de uma diferença muito clara entre uma forma de pensar a imagem como um signo e uma forma de pensar a imagem como símbolo. A imagem como um signo é uma imagem que significa, ou seja, ela já está objetificada, como um sintoma. A imagemsímbolo por outro lado, remete a alguma "coisa", ele aponta sentidos, não significados. 0 símbolo não pode ser reduzido a uma forma de interpretação única, ele não significa. 0 símbolo é sempre ambíguo, remete a uma construção de compreensão mais geral dos fenômenos relacionados e envolvidos com a imagem, ele aponta indícios, mas não determina o que é. Ele nunca se põe como efeito direto de, ou causa direta de. Ele pode até ser lido como portador de um significado, na atualização de um contexto, mas jamais reduzir-se a esse. Em outras palavras: "O conteúdo do imaginário do impulso pode ser interpretado... redutivamente, ou seja, semioticamente, como a própria representação do impulso ou, simbolicamente, como sentido espiritual do instinto natural [...]" (JUNG, 1954, p. 17-23).

Essa imagem simbólica com um sentido espiritual é o que Jung chama de arquétipo. 0 arquétipo é uma dinâmica do pensamento sem forma exata, uma confluência de virtualidades que cria um sistema de forças psíquicas no inconsciente. Esse sistema ganha uma expressão imagética quando a consciência clara lhe atribui uma forma sensível de ser habitada e por consequência significada. "O arquétipo é, portanto, uma forma dinâmica, uma estrutura que organiza as imagens, mas sempre ultrapassa as concretudes individuais, biográficas, regionais e sociais da formação das imagens [...]" (DURAND, 1988, p. 60). Então, o arquétipo acontece no efeito-signo, mas sempre o ultrapassa, o que faz com que a energia psíquica esteja no eterno fluxo entre suas instâncias concretas e individuais e de volta a uma dimensão cósmica, inconsciente e coletiva de estrutura numinosa da psique.

Essa dimensão inconsciente que se enreda e nutre nossa dimensão consciente é o que tratamos aqui como imaginário. Acrescentamos agora a essa ideia um componente de autonomia, de organização de suas estruturas arquetípicas em completa ressonância e retroalimentação com os acontecimentos da dimensão "realista" do mundo. Ou seja, o imaginário possui sua própria forma de organização e essa autonomia é o que inspirou Edgar Morin (1998) na sua apropriação do conceito de Noosfera. Morin parte da inspiração de Teilhard de Chardin, que na primeira metade do século passado partiu de uma compilação da clássica ideia da constituição do planeta fatiado em camadas: 
Os geólogos, de há muito, concordam em admitir a composição zoneada de nosso planeta. Já nos referimos a Barisfera, metálica e central, - rodeada por sua Litosfera rochosa, -à qual, por sua vez, se sobrepõem as camadas fluidas da Hidrosfera e da Atmosfera. A essas quatro superfícies encaixadas entre si, a Ciência habituou-se com razão a acrescentar a membrana viva formada pelo feltro vegetal e animal do globo: a Biosfera [...]. (CHARDIN, 2004, p. 197).

Chardin apresenta uma nova camada entrelaçada na biosfera, uma outra esfera formada pelos seres do pensamento, pelas aspirações, medos e razões criadas pela engenhosidade do espírito humano. Deu a essa zona o nome de Noosfera ${ }^{1}$ como camada pensante da terra, um novo reino entrelaçado, mas distinto da biosfera.

Sobre o conceito de Chardin, Edgar Morin constrói uma compreensão maior e mais rica de autonomia, deslocando a Noosfera do universo cristão do padre jesuíta para uma ideia que em muito se assemelha a relação dos gregos com seus deuses, semideuses e mitos.

De minha parte, convencido desde muito tempo da realidade do mundo imaginário/mitológico/ideológico (Morin, 1956), convencido de que esse mundo certamente é um produto de seu próprio produtor antropossocial, fui sensibilizado pela concepção de Auger/Monod que considerava a noosfera não mais como um mundo abstrato de objetos ideais, mas como um mundo fervilhante de seres dispondo de algumas características essenciais dos seres biológicos; fui assim estimulado a explorar o problema da autonomia relativa e da relação complexa (da simbiose à exploração mútua) entre esses seres de espírito e os seres humanos. 0 caminho estava aberto para que eu imaginasse não somente uma noosfera povoada de entidades 'vivas', mas também a possibilidade de uma ciência das ideias que seria, ao mesmo tempo, uma ciência da vida dos seres de espírito: uma noologia. (MORIN, 1998, p. 143).

Para Morin, os seres humanos criam e são criados pelos seres pensantes, numa relação de retroalimentação constante. 0 que nos leva a nossa última referência, o conceito de Trajeto antropológico, de Gilbert Durand (1988).

Na reflexão deste conceito, as sociedades humanas constroem seus sistemas de ideias e valores enraizando-os desde cedo em nossa formação. Quando ainda crianças, compreendemos por imagens afetivas o enaltecimento ou julgamento de comportamentos e crenças. Corpo e mente introjetam essas imagens e essas, por sua vez, alimentam nossa vida em sociedade. Na sociedade, por sua vez recriamos e atualizamos coletivamente a força dessas inspirações de mundos, que percorrem de volta ao mundo dos seres pensantes e pensados o seu trajeto antropológico. Em resumo, a energia psíquica circula dos mundos imaginários à sociedade, da sociedade à formação biopsíquica, dessa de volta à sociedade, e

\footnotetext{
${ }^{1}$ Chardin criou esse neologismo por um lado a partir do grego nous, que aponta a ideia de espírito, psique e por outro do latim sphaera, que indica a ideia de esfera.
} 
o ciclo se fecha em retorno ao imaginário, sem que haja um ponto de partida e um ponto de chegada. 0 imaginário não veio primeiro e o corpo-mente depois. Eles se co-criaram simultaneamente. Esse é o conceito de trajeto antropológico da energia psíquica na organização simbólica e que existe como o grande patrimônio compartilhado de nossa espécie.

Foi nesta chave conceitual do trajeto antropológico que apresentamos no item anterior o movimento criativo da imaginação das invenções tecnológicas que se materializam encantando e aterrorizando. Esses efeitos sensíveis propagados no mundo ressoam de volta em suas imagens de base no imaginário, compondo novos aspectos, que lá ficam à espera de condições criativas para novos esboços, e tecnológicas, e para novas materializações.

Dessa forma, compreendemos o quanto as imagens possuem força. 0 quanto elas dizem do que somos da forma mais íntima de nossas aspirações e temores. As imagens que criamos estão ligadas em cadeias profundas de relações com o que nos formou e certamente apontam o que ansiamos, as construções que fazemos de como será o nosso futuro. Da mesma forma que pudemos perceber um futuro previsto pelas páginas de romances nos séculos passados, bem como nos traços de desenhos rascunhados, é possível continuar esta percepção sobre formas mais atuais de registro.

Unindo a capacidade narrativa dos romances ao poder evocativo das imagens, temos hoje um grande representante das manifestações de imaginário de futuro nas salas de projeção ao redor do mundo. 0 cinema, compreendido enquanto linguagem e não apenas como dispositivo midiático tem construído diversas versões de futuro para a humanidade e servido como catalisador contemporâneo das materializações científicas, ambientais e sociais que antes só existiam no imaginário coletivo.

\section{0 cinema e o futuro}

O cinema possui uma gênese nebulosa que remonta não apenas à França do final do século XIX, com a famosa exposição do cinematógrafo dos irmãos Lumiére, mas sim uma verdadeira gama de invenções e experiências estéticas em todo o globo, em distintas épocas. Seria imprudente falar da sétima arte como nascida em 1895, haja vista que ela se constrói em um percurso que soma outros avanços tecnológicos como a lanterna mágica e os dispositivos de animação como o fenaquistoscópio e o zootrópio. 
Para Arlindo Machado (2011), essa origem vai ainda mais distante, quando as pinturas das cavernas eram fruídas através do uso de tochas. Enxergar as obras registradas nas paredes de lugares tão escuros exigia o manuseio da luz artificial dos antigos contempladores. As pinturas, portanto, foram feitas para serem vistas por um observador que caminha por elas, iluminando-as gradativamente e de forma sequencial, o que muitas vezes pode conferir às imagens a impressão de movimento.

Complementar à experiência narrada por Machado, podemos ressaltar aqui a análise feita por Gombrich (1999) sobre o poder primitivo das imagens. Segundo o autor, as imagens possuíam função definida e não eram vistas apenas como decorativas. No caso das pinturas rupestres deste pré-cinema, as ilustrações eram parte de um ritual mágico que tinha seus objetivos práticos na vida dos artistas.

A explicação mais provável para essas pinturas rupestres ainda é a de que se trata das mais antigas relíquias da crença universal no poder produzido pelas imagens; dito em outras palavras, parece que esses caçadores primitivos imaginavam que, se fizessem uma imagem de sua presa - e até a espicaçassem com suas lanças e machados de pedra -, os animais verdadeiros também sucumbiriam ao seu poder. (GOMBRICH, 1999, p. 42).

Trata-se desta experiência primitiva de cinema - ou puramente da imagem funcionando como um prenúncio do que viria a ser. De alguma forma, se acreditava que uma vez registrada a imagem, o futuro poderia se descortinar para concretizá-la. Podemos enxergar que este misticismo se perdeu com o tempo, devido à banalização das imagens através de sua reprodutibilidade técnica ou a perda de sua aura original (BENJAMIN, 1987), mas algum resquício desta função mágica ainda ecoa nas telas de cinema atuais.

O próprio Arlindo Machado (2011) ainda ressalta haver uma correlação muito forte entre a experiência cinema ${ }^{2}$ e a caverna descrita por Platão, onde através das sombras projetadas na parede era possível construir uma leitura ilusória de um mundo pleno a ser desbravado do lado de fora. Na caverna de Platão, segundo o autor:

A luz que projeta as sombras na tela-parede é artificial, obtida por intermédio de um fogo que queima por detrás dos prisioneiros [...]. Tal fogo encontra-se estrategicamente colocado atrás e acima das cabeças dos prisioneiros, pois Platão sabia muito bem que, colocado em outro lugar, o foco de luz faria projetar os próprios espectadores na tela, desvelando, portanto, o dispositivo. (MACHADO, 2011, p. 32)

\footnotetext{
${ }^{2}$ Diz-se da experiência que exige isolamento em sala escura, sem intervenções externas, onde o público está em silêncio, frente a uma tela luminosa. Machado nomeia essas condições da fruição ideal do cinema de experiência cinema.
} 
Assim como na caverna de Platão, o cinema também tem servido para nos revelar um mundo que ainda precisa ser desbravado. Podemos enxergar que o exemplo primitivo do cinema das cavernas trabalhava com a magia de evocação do futuro, enquanto aqui estamos diante de um mundo mais amplo e intenso, cheio de possibilidades, que pode ser revelado pelas simulações da sétima arte. Se observarmos estes dois exemplos e buscarmos neles uma intersecção, iremos vislumbrar uma capacidade ancestral do cinema de nos revelar algo que desejamos, provocando-nos a busca. Podemos aplicar às funções do cinema a capacidade de nos instigar a construção de um futuro que antes só existiria por trás da sua tela luminosa?

Esta capacidade de moldar o futuro com base na ficção e no imaginário no presente não é um fator novo na história da humanidade. Lembremos aqui as inúmeras lendas e lugares lendários que já motivaram expedições desbravadoras na Idade Média, por exemplo. Muitas foram as jornadas já feitas, que tinham por objetivo encontrar lugares míticos por diversos reinos, e todas elas serviram para que a humanidade alcançasse terras desconhecidas, ampliasse seu conhecimento de mundo e se firmasse no domínio dos seus territórios.

Dentre várias lendas que já foram tomadas por reais, Eco (2013) relata algumas que moveram verdadeiras cruzadas das civilizações antigas, como, por exemplo, a existência do reino de Preste João, a partir do século XII. O lugar de seres monstruosos, esplêndidos palácios e muitas riquezas era um reinado cristão no meio do extremo Oriente e foi procurado por João de Pian del Carpine, Guilherme Rubruck e Marco Polo em suas viagens para a Mongólia e China no século XIII (ECO, 2013). Segundo o autor, até mesmo o nazismo bebeu da fonte das lendas quando baseou sua teoria de superioridade ariana sobre a crença na raça dos hiperbóreos, supostos habitantes do norte da Europa.É possível, pelas inúmeras e ricas descrições de Umberto Eco, elencar dezenas de histórias que a humanidade já tomou por reais, vivendo-as em seu dia-a-dia, tomando-as por bússolas para suas peregrinações. De certa forma, o imaginário destes eventos, lugares e personalidades estava afetando o mundo físico real destas gerações. 0 estudioso afirma que:

Existiram terras longamente sonhadas, descritas, procuradas, registradas em mapas, que mais tarde sumiram dos mapas e hoje todos sabem que jamais existiram. No entanto, estas terras tiveram, para o desenvolvimento da civilização, a mesma função utópica que teve o reino do Preste João, em busca do qual os europeus exploraram a Ásia e a África, encontrando, é claro, outras coisas. (ECO, 2013, p. 326). 
Ao longo da história das mídias, esta ficção - ou mito - conseguiu igualmente reger diversos movimentos da humanidade rumo ao futuro. Podemos elencar grande número de filmes que retiraram da imaginação humana um vasto repertório de tecnologias e comportamentos futuristas que, com o passar dos anos, tornaram-se realidade. Qual o papel do cinema e das mídias em geral na construção do futuro? 0 imaginário que jorra pelas telas pode ter ainda a velha função mágica de evocar um futuro desejado, ou talvez estejamos apenas diante da caverna de Platão, que nos revela as sombras de um mundo real a ser descoberto.

\section{Traçando um percurso entre ficção e realidade}

A mente diante de uma narrativa passa por uma construção de experiência que já foi analisada por diversas áreas do conhecimento. Aristóteles (2008), como um dos primeiros teóricos a abordar o assunto, menciona a catarse como forma de purificação do público através da compaixão e/ou temor evocados pela tragédia grega. A arte da imitação do real, segundo ele, era capaz de nos fazer expurgar emoções a partir do momento em que assistíamos ao outro atuando. Esse envolvimento emocional com a tragédia é um ponto de partida para o conceito de "complexo projeção-identificação-transferência" explorado por Edgar Morin (1983).

Embora esteja teorizando a experiência de fruição do cinema, o complexo de Morin também diz respeito a uma comoção do público diante da ficção audiovisual, onde se percebe que existe a transferência da sua dor para a dor do outro, uma espécie de projeção do eu que se apaga na sala escura do cinema na direção do eu que se assume ser na tela de projeção. Em outras palavras, uma relação de troca entre a audiência e o personagem com o qual ela se identifica. Percebe-se que, seja no teatro ou no cinema, estamos diante de uma reflexão que compreende a ficção como a experiência de um abraço de vidas imaginárias da audiência com os personagens.

A psicologia cognitiva também teoriza a esse respeito, ao nos colocar diante da metáfora de viagem aos chamados textos miméticos. Estes textos, que tomam também de Aristóteles o conceito de mimesis, são compreendidos como todo aquele que constrói um mundo narrativo, envolvendo o indivíduo fruidor em lugares e ações descritas, sejam elas puramente ficcionais ou não (MARTíNEZ-BONATI, $1981^{3}$ apud RYAN, 2001, p. 92) ${ }^{4}$. Neste

\footnotetext{
3 MARTÍNEZ-BONATI, Félix. Fictive discourse and the structures of literature: a phenomenological approach. Silver. Ithaca: Cornell UP, 1981.
} 
mesmo raciocínio, Richard Gerrig menciona que ao lermos um romance somos transportados para o mundo do texto, de onde retornamos transformados, assim como Victor Nell menciona que construímos nesta experiência um envolvimento com a leitura, o qual se aprofunda até camadas patológicas de dependência do universo ficcional (RYAN, 2001, p. 93-98).

Seja qual for a perspectiva, é nítido que há na experiência de fruição da narrativa um elemento exclusivamente humano que perpassa a interpretação de signos e compreensão de enredos, mas não se resume a isto. Há uma ligação entre mente e universo ficcional que atinge as emoções, que nos capacita para a própria vida além dos limites do palco, da tela ou das páginas do livro. Ir até o mundo textual e retornar de lá transformado é uma analogia muito cara para o processo que estamos analisando neste estudo. Se toda ficção abre-nos as portas para que possamos adentrar seus domínios e vivenciá-los para que de lá voltemos à realidade, é certo que muito das construções ficcionais são composições híbridas entre um imaginário atualizado (aquilo que muitos chamam de realidade) e um imaginário irreal (o que chamam de imaginação). Logo, usamos a expressão Realidade aqui, apenas para apontar o lugar de acontecimento do imaginário, não cabendo qualquer distinção de natureza entre a realidade e a imaginação, mas apenas uma diferença de grau de realidades.

Dito isto, podemos então entender que a narrativa de futuro pode funcionar como catalisadora de avanços tecnológicos? Podemos dizer que as narrativas e suas gradações do Maravilhoso ao Fantástico podem ser lidas como verdadeiras camadas do imaginário, onde as ideias pairam totalmente inverossímeis (ou por vezes ilógicas) na superfície, mas decantam no substrato do fantástico, em uma forma mais próxima da dimensão de realidade. Segundo Tzvetan Todorov, o Maravilhoso é o gênero literário que nos apresenta narrativas que não nos deixam dúvidas quanto à fantasia do mundo relatado. Isso vai desde o conto de fadas até a ficção científica, em subdivisões que o autor detalha em seu livro Introdução à literatura fantástica (1992). 0 fantástico, por sua vez, recai no limbo da dúvida entre a narrativa de fatos reais ou imaginários. Um exemplo dado pelo autor é o de histórias que envolvem manifestações demoníacas, quando afirma que:

\footnotetext{
4 "The concrete character of the objects that populate textual worlds limits the applicability of the concept to a category of texts that Félix Martínez-Bonati [(1981)] calls mimetic texts. This term refers to texts devoted to the representation of states of affairs involving individual existentes situated in time and space, as opposed to those texts that deal exclusively with universals, abstracts ideas, and atemporal categories. We can roughly equate mimetic texts with narrative texts, though their evocation of particular existents does not necessarily fulfill the conditons of closure and coherence tat we associate with the notion of plot." (RYAN, 2001, p. 92)
} 
Ou o diabo é uma ilusão, um ser imaginário, ou existe realmente, como outros seres, com a diferença de que rara vez o encontra. 0 fantástico ocupa o tempo desta incerteza. Assim que se escolhe uma das duas respostas, deixa-se o terreno do fantástico para entrar em um gênero vizinho: o estranho ou o maravilhoso. (TODOROV, 1992, p. 15-16).

Caso pensemos nestas narrativas de futuro, poderemos ver que há, no trajeto até a possibilidade de sua manifestação no mundo, uma gradação que perpassa os graus de Todorov que vão desde o Maravilhoso hiperbólico, passando pelo exótico, instrumental e, por fim, a ficção científica. Entrar no campo do fantástico, portanto, significa também entrar na hipótese de realização dos fatos narrados. O que estamos pontuando, portanto, é a capacidade do imaginário atuar na já referida Noosfera assim como a água atua na atmosfera, em seu ciclo que já nos é de percepção tão natural. Assim como a água paira, livre, nas camadas superiores da atmosfera até que se acumule e caia sobre a terra na sua forma líquida, as ideias também parecem pairar livres no contexto Maravilhoso das criações narrativas até que a ciência e a sociedade lhe proporcionem um agrupamento de condições para que caia das camadas altas, dotadas de alguma possibilidade de materialização. Entretanto, a água sempre será água, no estado líquido, sólido ou gasoso. 0 imaginário sempre será o imaginário, seja nas zonas mais virtuais do pensamento até a mais complexa máquina de guerra em atuação no mundo.

Propomos, então, enxergar o imaginário como detentor de certa gradação de verossimilhança. Ideias do imaginário ganham forma e densidade, tornam-se acessíveis e colocam-se dispostas à mente humana como fonte de inspiração para transformarmos o fato imaginado em Acontecimento. Ou seja, o que se coloca como imaginário aqui traz uma diferença de graus de realização dos mais virtuais aos mais atuais, mas nunca uma oposição de natureza com o real. 0 que era impensável há dois séculos, tomando forma agitada de partícula de superfície no imaginário, hoje pode decantar até zonas de transição entre as camadas do imaginário verossímil possível - o fantástico - e o mundo atual, simplesmente pelo fato de que a ciência, hoje, permite-nos pensar tais elementos não mais segundo a sua impossibilidade, mas sim de acordo com os alcances reais da ciência.

\section{Conclusão}

Nesta profunda relação entre as imagens que criamos e o tempo, poderíamos olhar para o passado e imaginar quais as nossas necessidades que insistimos em reapresentar na 
produção imagética contemporânea. 0 que é isso que persiste e que insiste no tempo, nos trazendo mais de nós mesmos, desse antropos comum que se expressa por imagens? Estava exatamente aí a busca obstinada de Aby Warburg ao longo de toda sua curta carreira de iconologista.

Mas se a imagem é a persistência do tempo que passou, ela também aponta o que pode persistir no futuro. Ela também acontecerá muitas vezes, criando mundos de ficção a partir do repertório de desejos antigos. Sobre a imagem temos, então, muito o que aprender. Na imagem que criamos hoje, em nossos filmes de ficção científica sobre o amanhã, quais desejos, medos, esperanças ou desesperos apontamos em nossa construção coletiva do imaginário do futuro?

Ser espectador de uma narrativa de futuro pode ser interpretado como uma experiência que vai muito além de uma fruição momentânea de momentos catárticos isolados. A boa narrativa futurística preza pela possibilidade de realização vindoura de seu conteúdo científico, pautando-se nas projeções das mais variadas ciências, considerando-se também aspectos da vida em sociedade e da própria situação da biosfera diante dos direcionamentos que a humanidade tem tomado. Histórias que tratam de um mundo em escassez hídrica, como nos filmes da franquia Mad Max (1979, 1981, 1985, 2015), por exemplo, podem não ser resultado de apontamentos de avanços tecnológicos, mas se tornam visões possíveis de futuro diante de uma humanidade que esgota suas fontes de água na atualidade.

Narrativas de futuro, sobretudo no cinema, parecem construir materializações de ideias que partem de construções impossíveis, entretanto, ganham credibilidade ao longo da história da humanidade, nutridas pelos avanços a passos largos da ciência. 0 imaginário se constrói, dessa forma, como um limbo de camadas que tendem à decantação de elementos imaginados, os quais servem de fonte de inspiração para a transformação da realidade.

Estas histórias, se observadas por outra perspectiva, não servem apenas para antecipar o que viremos a conquistar/sofrer no futuro, mas podem ser entendidas também como experiências de reflexão sobre o que estamos construindo hoje. Viajar a estes mundos das imagens e trazer de lá algo que nos faça diferentes pode significar não apenas a chegada de novas possibilidades de inovação tecnológica, mas também um ato reflexivo a fim de evitar o futuro projetado. Narrativas de futuro, portanto, revelam-se como muito superiores a simples momentos lúdicos de fruição, pois podem representar tanto o que está por vir 
quanto o que não podemos deixar que aconteça, tornando-se, assim, um forte instrumento para pensarmos os limites da nossa sociedade.

\section{Referências}

2001: a space odyssey. Direção: Stanley Kubrick. Roteiro: Stanley Kubrick e Arthur Charles Clarke. [S. l.]: Metro-Goldwyn-Mayer; Stanley Kubrick Productions, 1968.

ARISTÓTELES. Poética. 3. ed. Lisboa: Fundação Calouste Gulbenkian, 2008.

BENJAMIN, Walter. Magia e técnica, arte e política: ensaios sobre literatura e história da cultura. 3. ed. São Paulo: Brasiliense, 1987. v. 1.

CAPRA, Fritjof. A ciência de Leonardo da Vinci. São Paulo: Cultrix. 2008.

CHARDIN, Teilhard de. 0 fenômeno humano. São Paulo: Cultrix. 2004.

CLARKE, Arthur Charles. The sentinel. [S.l.: s.n.], 1951.

DURAND, Gilbert. A imaginação simbólica. São Paulo: Cultrix. 1988.

ECO, Umberto. História das terras e lugares lendários. Rio de Janeiro: Record, 2013.

GOMBRICH, Ernst Hans. A história da arte. 16. ed. Rio de Janeiro: LTC, 1999.

HUXLEY, Aldous. Brave New World. [S.l.: s.n.], 1932.

JUNG, Carl Gustav. La psicologia de la transferencia. Buenos Aires: Paidos, 1954.

MACHADO, Arlindo. Pré-cinemas \& pós-cinemas. 6 ed. Campinas: Papirus, 2011.

MAD Max. Direção: George Miller. [S. I.]: Kennedy Miller Productions, 1979.

MAD Max 2: the road warrior. Direção: George Miller. [S. l.]: Kennedy Miller Productions, 1981.

MAD Max 3: beyond thunderdome. George Miller. [S. l.]: Kennedy Miller Productions, 1985.

MAD Max: fury road. George Miller. [S. l.]: Kennedy Miller Mitchell; 2015.

MORIN, Edgar. A alma do cinema. In: XAVIER, Ismail. (Org.) A experiência do cinema: antologia. Rio de Janeiro: Graal, 1983.

MORIN, Edgar. 0 método 04: as idéias. Porto Alegre: Sulina. 1998.

ORWELL, George. 1984. [S.l.: s.n.], 1948. 
RYAN, Marie-Laure. Narrative as virtual reality: immersion and interactivity in literature and electronic media. London: The Johns Hopkins University Press, 2001.

TODOROV, Tzvetan. Introdução à literatura fantástica. 2. ed. São Paulo: Perspectiva, 1992.

VERNE, Jules. Vingt mille lieues sous les mers. [S.l.: s.n.], 1870.

VERNE, Jules. De la Terre à la Lune. [S.l.: s.n.], 1865.

VERNE, Jules. Voyage au centre de la Terre. [S.l.: s.n.], 1870.

WELLS, Herbert Georg. The war of the worlds. [S.l.: s.n.], 1898.

\title{
Image beyond time: the construction of the imaginary of the future in media products
}

\begin{abstract}
The imaginary has served mankind as a great source of speculation for the future. Over the centuries, inventions considered impossible achievements have become reality and have left the papers to assume their physical spaces in people's daily lives. Whether it's represented by Da Vinci projects, Jules Verne's literature or even the Méliès films, the science-fiction media has been a catalyst for real transformations in technology and society, besides it has helped us think about the present itself based on our projections of what is to come. This text focuses on the imaginary and some media expressions, especially the cinema, to point out a perspective of interpretation of futuristic narratives that goes beyond its ephemeral playful moment of fruition. The seemingly simple act of imagining and simulating the future through the media, in this way, may prove to be a strong exercise of human mental rehearsal for what it will eventually acquire.
\end{abstract}

\section{Keywords}

Imaginary. Future. Cinema.

Recebido em 27/01/2017

Aceito em 05/06/2017 